\title{
What are the real risks for tailings facilities?
}

\author{
BS Brown Bruce Brown Consulting Pty Ltd, Australia
}

\begin{abstract}
The movement towards risk-based design and operation of tailings storage facilities (TSFs) has taken place over the last few decades. The establishment of the consequence of failure of a facility is used to determine the design criteria to be used in its design. These criteria generally set the acceptable return periods for seismic and hydrologic events that the facility must accommodate. In addition, there are generally several levels of risk assessment of the design carried out to highlight technical risks that require particular attention and controls to manage. These are usually addressed in the design phase of project development.
\end{abstract}

Despite this focus on technical risk assessment at the design phases of the development of a TSF, there is still a significant number of failures occurring every year. In recent times, there have been a number of high profile TSF failures in facilities owned by major mining houses and/or located in highly regulated, first world countries. In almost every case, the investigations into the failures have been carried out by high profile, internationally recognised geotechnical engineers who have identified the technical reasons for the failure.

In many cases, it has been shown that the root causes of the failures have been a failure in governance, capital constraints, change management, independent reviews, construction supervision, operation, etc. The investigation of failures and reports to the public are almost exclusively focused on the technical cause with much less focus on what is often the underlying root cause.

A number of international mining industry groups have recognised the lack of effective governance as being a major risk that could lead to TSF failures. The Mining Association of Canada (MAC) and the International Council on Mining and Metals (ICMM) are two examples.

In this paper, the various methods for risk assessment and management are described. Non-technical risks that arise in the design and operation of TSFs are discussed and importance of good governance and continuity of its application during the full lifecycle of the facilities is emphasised.

Keywords: risk assessment, non-technical risks, tailings management, governance

\section{Introduction}

The move towards risk-based design was to rationalise the choice of return periods for seismic events and rainfall and flooding events, and to identify, assess and provide controls for risks that could directly, or in concert with other risks, lead to unwanted outcomes. Prior to this, the choice of these design criteria was somewhat ad hoc. A return period of 100 years for precipitation events was often considered appropriate in many cases. However, for a design life of a facility of, say, 20 years, the probability of exceedance is approximately $20 \%$ over the life of the facility. It became apparent that this was not an acceptable risk and that a more structured approach was required to determine the appropriate design criteria based on the consequence of failure. A number of design guidelines were developed, including the Canadian Dam Association's (CDA) 'Dam Safety Guidelines' (CDA 1999) and the Australian National Committee on Large Dams' (ANCOLD) 'Guidelines on Tailings Dam Design, Construction and Operations' (ANCOLD 1999). These, and similar guidelines developed by other jurisdictions and organisations have been revised and updated as a result of recent high level tailings facility failures, and are now in standard usage to determine the appropriate design criteria that limits the likelihood of catastrophic events for the appropriate level of consequences of failure. 
Risk assessment methods have been developed to identify threats that could lead to unwanted events up to, and including, catastrophic failure. The risk assessment estimates likelihood and consequences of the threats, and taking the effectiveness of existing controls into account, assigns a risk level. Often, non-technical risks are not recognised or assessed. These risks relate to a failure of governance and are shown in most cases to be the root cause of failures and, therefore, represent the 'real' risks for tailings facilities.

There has been a number of guidelines, standards and procedures prepared by mining industry associations, government agencies and mining companies for internal use. These are similar in scope and require accountability, adequate planning and resourcing, risk assessment, change management, emergency preparedness and independent reviews. These are to specifically address the non-technical or 'real' risks for tailings facilities.

\section{$2 \quad$ Risk assessment methods}

There are a number of methods in standard practice for the identification and classification of risks associated with tailings storage facilities. These range from qualitative to semi-quantitative, to fully quantitative methods. Qualitative methods are simply ones where the potential threats are identified without any attempt to establish a likelihood. These are typically used at the beginning of a project to raise potential 'red flags'. The semi-quantitative methods establish likely consequences and assign broad likelihoods to the threats. The quantitative methods attempt to assign probabilities to the identified consequences to arrive at a more definitive risk analysis.

\subsection{Semi-quantitative risk assessment}

The risk assessment of TSF designs in the conceptual, feasibility and detailed design stages is now an integral part of the design process. Similarly, ongoing risk assessment during operations is standard practice. The risk assessment methodology can range from the semi-qualitative to the fully quantitative. The most common method is the semi-quantitative method. A potential hazard is identified and the maximum credible consequence is determined. The likelihood of this hazard occurring that results in this consequence is estimated. The combination of the consequence and likelihood determines the risk level, and this drives the level and timing of mitigative measures and critical controls needed to reduce the risk to an acceptable level. A typical risk assessment matrix is shown in Figure 1.

\begin{tabular}{llllll}
\hline Consequence & $\mathbf{1 - \text { minor }}$ & $\mathbf{2}$-medium & $\mathbf{3 - \text { serious }}$ & $\mathbf{4 - \text { major }}$ & $\mathbf{5}$-catastrophic \\
\hline Likelihood & & & & & \\
A-almost certain & Moderate & High & Critical & Critical & Critical \\
B-likely & Moderate & High & High & Critical & Critical \\
C-possible & Low & Moderate & High & Critical & Critical \\
D- unlikely & Low & Low & Moderate & High & Critical \\
E- rare & Low & Low & Moderate & High & High \\
\hline
\end{tabular}

Figure 1 Typical risk matrix for the determination of risk level

A critical risk level requires an immediate response to implement mitigative measures to reduce the risk to an acceptable level. A high risk is above the risk tolerance for the operation and requires specific, proactive management to reduce the risk level. It should be noted that the consequences of some risks would always be catastrophic, such as failure of a TSF embankment. In this case, the risk level will never be below high. This, therefore, will always require proactive management and monitoring to reduce and maintain the likelihood at rare. A moderate risk is usually below the risk threshold and requires a level of management and observation to ensure that the risk doesn't migrate to high. A low risk level needs to be watched. The mitigative measures are the controls required to manage the risks. These can include specialist input into 
design and construction specifications, operational quantifiable performance objectives, geotechnical and hydrotechnical monitoring, reviews, audits and inspections, among others.

The semi-quantitative risk assessment model should also be used to establish a risk register for an operating site. Risk workshops carried out by site operating staff, consultants and management identify and quantify risks and assign the appropriate risk mitigation measures and accountabilities. Semi-quantitative risk assessments can be used as a management tool to focus work on the areas that require the most attention and on the controls required for risk management.

The bowtie method focuses on a major hazard or top event, such as the catastrophic failure of a TSF embankment. A typical bowtie analysis is shown in Figure 2. The threats that could lead to the top event are identified and the existing controls for these threats are listed.

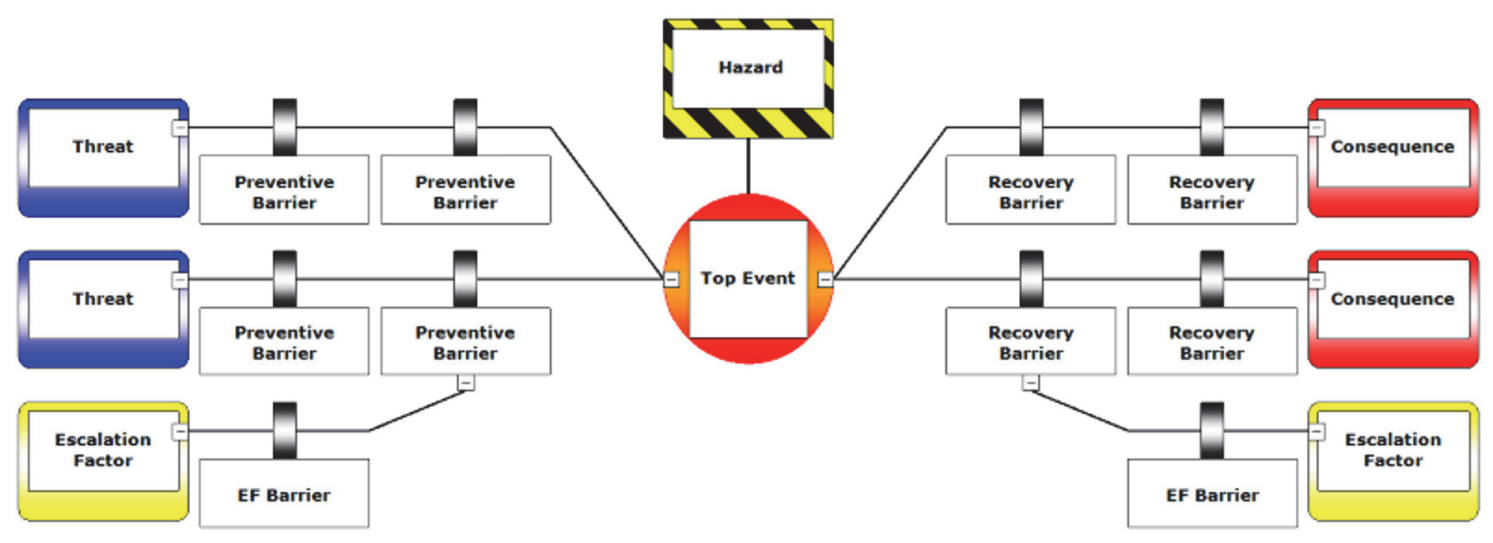

Controls

Harm minimisation

Figure 2 Typical bowtie risk assessment

The potential consequences of the top event are listed along with the recovery barriers or harm minimisation works. Likelihoods for the threats with the associated controls in place and the severity of the consequences with the associated minimisation works or controls are estimated. Risk levels for each threat are calculated by combining their likelihood with the level of each consequence. This can be done using semi-quantitative methods described previously in this paper or more rigorous quantitative methods to determine numerical estimates of probabilities.

A hazard and operability study (HAZOP) is a study of a design, construction, operation, etc. to identify potential risks and, where possible, identify solutions/mitigations for the risk. Unwanted outcomes and deviations from intended outcomes are identified, and the method works backwards to identify possible causes and failure modes.

\subsection{Quantitative risk assessment}

The Australian Standard SA SNZ HB 89-2013 'Risk management - Guidelines on risk assessment techniques' (Standards Australia 2013) provides a framework for quantitative risk assessment. There are a number of quantitative risk assessment methods. These include failure modes and effects analysis (FMEA), fault tree analysis (FTA) and event tree analysis (ETA).

The FMEA identifies all possible failure modes and the effect that these failures or combination or sequence of any of these failures would have on the facility being considered. Probabilities are assigned to each failure mode and combined probabilities of combinations of failure modes leading to facility failure are calculated. 
The FTA considers factors that can lead to an undesirable event. These are represented graphically in a tree diagram that shows the logical relationship between the causal factors to the undesirable event. Causal factors can include design errors, construction faults, operational failures, human errors and extreme events that could lead to the undesirable event. The fault tree can be used quantitatively to calculate the probability of the undesirable event by combining the probabilities of the causal events.

The ETA graphically represents sequences of events following an initiating event on the basis of the functionality of the systems designed to mitigate its consequences. Again, probabilities can be assigned to each event in the sequence to calculate the probability of various consequences following an initiating event.

\subsection{Assignment of probabilities}

A number of researchers have worked to develop defensible probabilities for individual events leading to failures. For example, Foster and Fell (1999) analysed the frequency of failure of embankment dams by piping considering the zoning categories in the dam sections, the age of the dam and whether piping occurred in the embankment, foundation or both. They pointed out that there was a degree of subjectivity in the development of these results. Probabilities for components leading to a failure are dependent on many factors, including quality of design and construction, level of site investigations, soil sampling and testing. The quality of each of these can vary the probability of component failure by orders of magnitude. Applying global statistics to determine the Probability of Failure for the components of a TSF can underestimate or overestimate the level of risk.

The level of acceptability of a Probability of Failure is a contentious issue and differs from county-to-country and jurisdiction-to-jurisdiction. The societal risk criteria for dam safety adopted by ANCOLD is shown in Figure 3. Generally, the cost of non-life/health threatening consequences can be calculated and a cost-benefit analysis can be applied to determine appropriate levels of control. There are, however, other not-so-tangible consequences such as company reputation, community outrage and licence to operate, that are much more difficult to quantify.

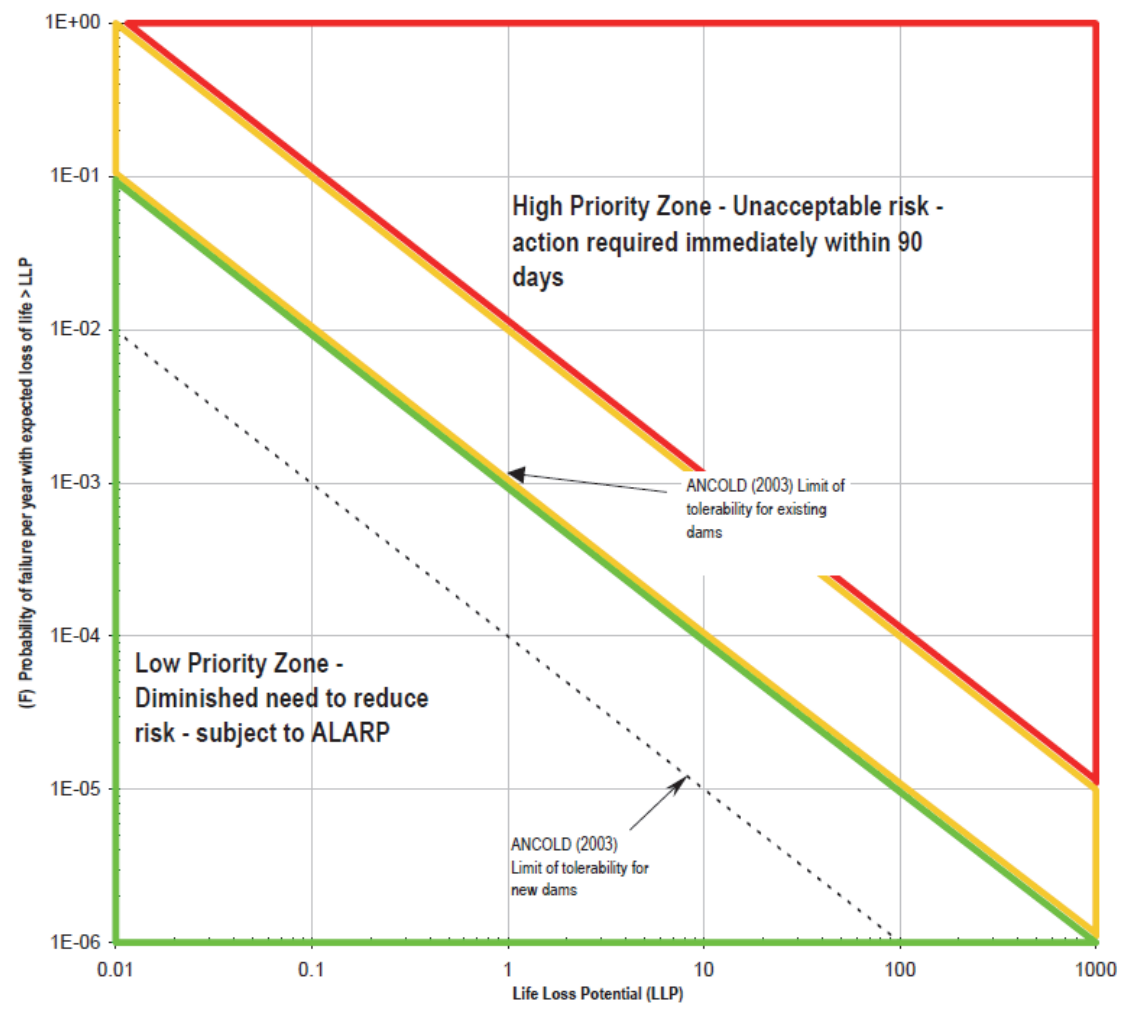

Figure 3 Societal risk criteria for dam safety 


\section{Recent failures}

Despite the advances in engineering science and risk management techniques, there continues to be failures on a regular basis averaging approximately two every year over the last few decades. Two high profile failures, Mount Polley in British Columbia, Canada, and Samarco in Brazil have had major impacts on the mining industry. Mount Polley was located in a highly regulated, first world country, and Samarco is owned by two of the largest mining companies. Investigations into these failures were carried out by internationally recognised geotechnical and tailings engineers. The investigations focused on the technical causes of the failures that determined the most likely failure mechanisms.

The failure of the Mount Polley embankment was determined to be the result of the embankment failing though a lacustrine silt layer in the embankment foundation, followed by erosion of the embankment by water released from the free water pond. There were a number of other investigations and reviews by government agencies that looked at the issues leading to the failure. These included significant changes in the design, operation and management of the facility. These changes, among others, included:

- The Engineer of Record was changed several years prior to the failure.

- The facility had a large free water pond impinging on the embankments, contrary to the original design intent.

- The embankment downstream slope was constructed to a much steeper slope than in the original design.

There is no record of formal change management that considered the potential impacts and changes in the risk profile as a result of these changes.

The failure of the Samarco TSF was due to a complex sequence of events that led to a static liquefaction failure of the embankment. The consequences of this failure are well-documented. The management issues leading up to the failure were specifically excluded from the brief of the review panel. There were, however, a number of changes and decisions made that led to the failure. These included, among others:

- Deviation from the design of the facility that allowed the deposition of fine tailings in what was intended to be the structural zone of the embankment.

- Remediation works to address some of the shortcomings of the facility, including failure of a drainage conduit and underdrain.

- Significant increase in the rate of tailings deposition into the facility.

Again, there is no public record of formal change management that considered the implications of these changes on the risks associated with the TSF.

\section{$4 \quad$ Non-technical risks}

It can be seen from Section 2 of this paper that there are well-developed risk assessment methodologies that consider all aspects of technical risk and that engineering science has been developed to a level that can analyse and mitigate almost all technical risks. The question is, 'Why do failures continue to happen?'. In almost every case, the root cause of the failure is in governance.

In addition to the critical risks that lead to catastrophic failures, there are numerous other risks that would not result in catastrophic failure but can lead to unwanted outcomes that have a major effect on the viability of a mining operation. Again, these risks are the result of poor management and governance.

Examples of risks that come about as a result of poor governance are discussed in the following sections. 


\subsection{Design changes}

In the design process, especially for greenfield sites, the design criteria for the TSF can change significantly. These can include changes in throughput, aggressive value engineering and changing siting constraints due to interaction with mining limits. These changes can take place while there are budget and schedule constraints that can resist the reset of the design process. This can lead to sub-optimal designs.

Tailings facilities are often designed on the basis of testwork on tailings from small laboratory-scale metallurgical testing or pilot plant runs. There is a risk that the tailings from the operating plant will have different characteristics that could affect the tailings consolidation and thereby the tailings density, filling rate and water management. Designs can be very sensitive to assumptions regarding tailings characteristics. An example is an assumption of tailings beach slope. A small variation in the beach slope can have a large impact on the storage basin filling and rate of rise of the tailings at the decant. In some cases, embankment crests have been sloped down from the deposition points to the decants to save on embankment volume. A flatter beach slope would then result in the need to raise the embankments/decants earlier than anticipated.

Value engineering can be carried out in the context of severe project cost pressures. The focus of the project development teams can be at odds with the operational teams. The project teams are concerned with budget and schedule and the operational teams want a facility that is easy to manage and operate. Deferring of capital expenditure to operating costs is often a way to minimise capital cost but can increase the operational risks.

\subsection{Construction}

The risk is that what is constructed does not comply with the intent of the designers. Often, once construction starts and the ground is broken, the conditions are not quite as anticipated in the design. The foundation conditions that were investigated by a limited number of drillholes can vary significantly from those adopted in the design. Borrow areas for embankment construction materials can be of limited extent and different in material characteristics. These issues can arise in the context of the drive to minimise cost and meet schedules.

\subsection{Operations}

The engineer designs on the basis that the tailings facility will be operated in a certain way. Very few TSF embankments are designed as water storage facilities and built to their final height without staging. Designs for TSF embankments often do not have the filters and drains normally associated with water dams, as it is assumed that the facility will be operated with tailings beaches adjacent to it, and the free water pond remote from the embankment. It is not uncommon for poor water management or extreme rainfall events leading to free water impinging on embankments. The designer may include upstream embankment toe drains or underdrains in the storage basin to reduce the water head on the embankments and foundations, or to enhance consolidation and increase the tailings deposit density. The pumps in the sumps that collect water from these drains are often neglected. The operational requirements of TSFs can require significant operator input to manage spigot rotations, water pond management, monitoring, etc. Successful operation requires trained staff that understand the reasons for operational requirements and the importance of meeting the key performance parameters. The staff turnover at many mines raises a risk that the importance of the operating requirements are lost or forgotten with the progression of new staff. This can be exacerbated if the new person managing the facility comes from a site where the TSF is operated in a different manner. 
Tailings storage facilities are almost always staged and constructed to the minimum heights necessary to accommodate the storage requirements needed. Upstream, and to a lessor degree, centreline staging of TSF embankments require the tailings deposit in the vicinity of the embankments to form part of the structure of the confining embankment. The operation of the tailings facility therefore needs to result in tailings being deposited and drained to a minimum density and strength to form a competent dilative material not susceptible to liquefaction. The risk is that operational upsets can result in pockets or layers of soft, contractive tailings unsuitable as a foundation for upstream raises. This can result in high-cost remedial changes to the embankment section, such as reverting to downstream construction or the need for stability berms.

\subsection{Mining and processing}

The focus of the operating plant is to maximise throughput and recovery as this drives revenue. Changes in grind size, reagents, flocculants, etc. are made to optimise the plant. These changes can have a profound effect on the tailings' behaviour. Consolidation and rheological characteristics can change, resulting in different tailings beach slopes, deposit density and water release. The increase in revenue from the changes in the plant needs to be compared with the increase in costs of operating the TSF (if any).

Orebodies are rarely uniform, and different ore types can produce tailings with different characteristics. While this is often accommodated by the plant, again there can be significant changes in tailings characteristics. A higher clay content can result in changes in settling, consolidation, beach slopes, etc.

The main risk with this is that the changes result in tailings characteristics that are outside the range of tailings characteristics the designers adopted in the design. Also, it is not unusual for TSF operators to become aware of the operational changes only when the behaviour of the deposited tailings changes. Change management is required to assess the impact of these changes and assess the change in risk profile in good time to amend designs, operating procedures, controls, etc. to accommodate these changes.

\subsection{Complacency}

The risk of complacency comes from a facility operating with little or no issues for a long period of time. The facility requires very little attention from senior management and often the responsibility for its operation is delegated to relatively junior staff. The reasons for the controls in place that have resulted in good performance are forgotten and as there are no problems, staff and resources are diverted to more pressing areas. Effective operational reviews, audits and active accountability from senior management are required to mitigate this risk.

\subsection{Mining cycle}

Davies and Martin (2009) investigated the correlation of TSF failures with the economic cycles of the mining industry and found that:

"There appears some validity to the hypothesis that the frequency of tailings dam incidents can be expected to increase some relatively short period after a cyclical "boom" in the mining industry."

This is somewhat surprising as it was expected that a downturn in the industry would lead to cost-cutting and operational constraints that would result in higher levels of risk.

In times of high commodity prices, there is a tendency to develop mines at a faster rate or increase the throughput of existing mines to capitalise on the higher prices. This can lead to severe scheduling pressures that can result in inadequate site investigations, incomplete options studies, incomplete designs with limited analyses, insufficient drawings and inadequate technical specifications. It is reasonable to assume that some or all of these factors could contribute to the increase in the number of TSF incidents. 


\section{$5 \quad$ Governance to manage risks}

The management of the risks described above is by the effective application of good governance. The ICMM (2016) developed elements of good governance in their global tailings management review, which was carried out as a result of the Samarco TSF failure. The six elements are:

- Accountability, responsibility and competency.

- Planning and resourcing.

- Risk management.

- Change management.

- Emergency preparedness.

- Review and assurance.

The accountability for the overall governance of tailings management resides with the highest level of the mine owner's management team. The responsibilities of the management team for the TSFs must be clearly defined and this team and the design consultants must have the appropriate level of training and experience to competently carry out their roles. Changes in management or designers can result in increased risk and should be subject to formal change management. Succession planning for internal managers must ensure that the design constraints and the critical risk controls are fully understood. Changing design consultants or Engineers of Record must ensure that the original design constraints and assumptions are fully understood by the new incumbent who has accepted full responsibility for the ongoing performance of the facility.

The long-term planning for life-of-mine tailings storage is essential to ensure that there are sufficient resources, including personnel and capital allowances, schedule to carry out investigations, design, permitting and construction in a timely manner. Any changes in the long-term plan due to financial constraints, changes in the mining cycle, etc. that affect the available resources or schedule for the facilities must be subject to formal change management.

Risk management must be carried out to identify and assess technical and non-technical risks, as described in this paper. The assessment should include the risk mitigations and controls, verification and reliability of controls, and assignment of risk ownership to individuals. The purpose of risk management is to identify the risks and the critical controls required to mitigate these risks. The ICMM (2018) have developed a guideline for the management of critical controls needed to prevent an undesirable event from happening.

Change management is the most important tool to prevent unanticipated risks. Change management should set out the details of the change, identify all affected parties and processes, and identify the risks to all affected parties that would result from the change. The benefits of the change should be assessed against the associated risks. The option of no change should be assessed. An informed decision can then be made to go forward with the change or not. Effective change management procedures are not well-established or implemented in many mining operations.

Emergency preparedness is a consequence-mitigation process. It sets out the actions required to respond to the abnormal to minimise impacts. Emergency preparedness is in two parts. The first part is the actions to be carried out when monitoring indicates that the dam is outside its safe operating range to prevent catastrophic failure. These actions or TARPs are usually presented in the facility operating manual. The second part is the emergency response plan to minimise the consequences of catastrophic failure. The plan is based on a dam break analysis that indicates the extent of the potential flooding that shows the number of people at risk, and the threatened environmental and infrastructure values. This plan must be developed with community consultation and input. The development of an emergency response plan is problematic for mining companies, particularly in the third world. It is difficult to discuss an emergency response plan for dam failure to downstream inhabitants while reassuring that the dam is safe. Notwithstanding this, it 
must be done. The United Nations Environment Programme (UNEP 2015) has prepared a guideline for the preparation of emergency response plans.

Review and assurance is an essential part of TSF risk management. The level and frequency of reviews and audits are generally based on the overall risk level assessed for the facility. Industry associations and government regulations generally require independent design reviews and operational reviews and audits. There is a move towards the appointment of high-level independent technical review boards to oversee the design, construction and operation of the facilities. After the Mount Polley failure, review boards were made mandatory in British Columbia.

\section{Conclusion}

Risk management and risk-based design has become the state of practice in the management of tailings storage facilities. The tools for risk assessment are well-developed. Technical risks are well-known and engineering science has evolved to deal with these risks. The risks that are more likely to be overlooked are the non-technical risks that require good governance to implement and maintain the critical controls to prevent undesirable events.

\section{References}

ANCOLD 1999, Guidelines on Tailings Dams, Australian National Committee on Large Dams, Hobart.

CDA 1999 (revised 2007 and 2013), Dam Safety Guidelines, Canadian Dam Association, Toronto.

Davies, M \& Martin, T 2009, 'Mining market cycles and tailings dam incidents', in D Sego, M Alostaz \& N Beier (eds), Proceedings of the Thirteen International Conference on Tailings and Mine Waste, University of Alberta Geotechnical Centre, Edmonton, pp. 3-14.

Foster, MA \& Fell, R 1999, A Framework For Estimating The Probability Of Failure Of Embankment Dams By Internal Erosion And Piping Using Event Tree Methods, UNSW Sydney, Kensington.

ICMM 2016, Position Statement on Preventing Catastrophic Failure Of Tailings Storage Facilities, International Council on Mining \& Metals, London.

ICMM 2018, Critical Control Management Implementation Guide, International Council on Mining \& Metals, London.

Standards Australia 2013, SA SNZ HB 89-2013 Risk Management - Guidelines on Risk Assessment Techniques, Standards Australia, Sydney.

UNEP 2015, Awareness and Preparedness for Emergencies at the Local Level, United Nations Environment Programme, Paris. 
